\title{
PENETAPAN KADAR LOGAM BERAT TIMBAL (Pb) PADA EYE - LINER DENGAN METODE SPEKTROFOTOMETRI SERAPAN ATOM (SSA)
}

\author{
Muawanah $^{1)}$, Hamsina $^{2)}, \operatorname{Reva}^{1)}$ \\ ${ }^{1)}$ Prodi D3 Teknologi Laboratorium Medis Politeknik Kesehatan Muhammadiyah Makassar \\ ${ }^{2)}$ Balai Besar Laboratorium Kesehatan Makassar \\ Alamat Korespondensi: ummi.ahsan79@gmail.com
}

\begin{abstract}
Abstrak
Eye-liner merupakan sediaan kosmetik yang digunakan pada kulit tipis disekitar mata, oleh karena itu bahan yang terkandung didalamnya harus aman. Timbal (Pb) masuk kedalam tubuh manusia melalui jalur oral (makanan dan minuman), pernafasan, kontak melalui kulit, serta melalui parental. Efek berbahaya yang dapat ditimbulkan dari paparan logam timbal (Pb) bagi tubuh adalah sindroma abdomal, SSP, hematologi, renal dan neuromuscular. Tujuan penelitian ini yaitu untuk mengetahui kadar logam timbal $(\mathrm{Pb})$ pada sampel Eye-liner. Metode penelitian ini menggunakan metode Spektrofotometri Serapan Atom (SSA) pada panjang gelombang 283,3 $\mathrm{nm}$. Sampel Eye-liner dikumpulkan sebanyak 5 sampel dengan metode Purposive Sampling dimana kriteria yang ditentukan dalam penelitian ini adalah Eye-liner liquid, waterproof, yang seing digunakan oleh masyarakat dan dicurigai tercemar oleh logam berat timbal (Pb). Dari hasil penelitian diperoleh kadar timbal (Pb) masing-masing sampel adalah, sampel A sebanyak 2,2215 $\mathrm{mg} / \mathrm{kg}$, sampel B sebanyak 0,9226 mg/kg, sampel C sebanyak $18,7713 \mathrm{mg} / \mathrm{kg}$, sampel D sebanyak $1,2215 \mathrm{mg} / \mathrm{kg}$, dan sampel E sebanyak $5,7021 \mathrm{mg} / \mathrm{kg}$. Hasil penelitian tersebut dapat disimpulkan bahwa kelima sampel tersebut masih berada di bawah batas maksimum yang ditentukan yakni 20 ppm (20 mg/kg) menurut BPOM, sehingga masih dikategorikan aman untuk digunakan.
\end{abstract}

Kata Kunci: Eye-Liner, Logam berat Timbal, Spektrofotometri Serapan Atom (SSA)

\section{PENDAHULUAN}

Penggunaan kosmetik terutama di Indonesia dewasa ini semakin meningkat. Kosmetik merupakan bahan atau sediaan yang dimaksudkan untuk digunakan pada bagian luar tubuh manusia atau gigi dan mukosa mulut terutama untuk membersihkan, mewangikan, men gubah penampilan, menghilangkan bau badan, atau memelihara tubuh pada kondisi baik. Fungsi utama dari penggunaan kosmetik yaitu mempercantik diri pengguna agar tampak lebih menarik. Kosmetik pada umumnya bersifat kosmetik rias atau dekoratif atau pemeliharaan. Pemakaian kosmetik rias atau dekoratif dimaksudkan agar terlihat menarik serta dapat menutupi kekurangan yang ada (Winanti, 2011)

Salah satu jenis kosmetik dekoratif yang sering digunakan oleh masyarakat, terutama wanita adalah Eye-liner. Eyeliner digunakan untuk mempertegas garis mata agar terlihat lebih tajam dan menawan. Penggunaan Eye-liner pada kulit disekitar mata yang tipis dengan frekuensi yang berulang sehingga bahan yang terkandung di dalamnya harus aman (Winanti, 2011).

Beberapa produk kosmetik mengandung logam berat yang terdapat. Pada kosmetik apabila digunakan dapat menyebabkan beberapa gangguan pada kulit sehingga beberapa Negara, penggunaan logam berat telah dilarang. Negara Korea, Negara Eropa, Negara Cina telah melarang penggunaan timbal sebagai bahan dasar pembuatan kosmetika kulit (Fernier, 2001).

Seiring perkembangan zaman, logam timbal $(\mathrm{Pb})$ pada Eye-liner berfungsi sebagai pewarna dan dapat memberikan tampilan yang lebih menarik (Palar, 2012) karena timbal $(\mathrm{Pb})$ merupakan sejenis

Jurnal Medika: Media Ilmiah Analis Kesehatan Volume 4 Nomor 2, Desember 2019 ISSN:2540-7910 24 
logam yang lunak berwarna abu-abu kebiruan mengkilat serta mudah dimurnikan sehingga logam berat timbal $(\mathrm{Pb})$ mendapatkan perhatian karena bersifat toksik atau beracun (Novebry et al , 2015).

Timbal sering digunakan untuk melapisi logam agar tidak timbul pengkaratan, sebagai tambahan di dalam cat, baterai, dan bensin dan dapat terkandung dalam kosmetik sebagai cemaran, dimana cemaran adalah sesuatu yang masuk kedalam produk secara tidak sengaja dan tidak dapat dihindari yng berasal dari proses pengolahan, penyimpanan dan atau terbawa dari bahan baku (Novebry et al, 2015).

Timbal $(\mathrm{Pb})$ masuk kedalam tubuh melalui jalur oral (makanan dan minuman), pernafasan, kontak melalui kulit, serta melalui parental. Timbal $(\mathrm{Pb})$ merupakan racun sistemik dimana $\mathrm{Pb}$ anorganik mula-mula akan terdistribusi di jaringan lemak, terutama dalam ginjal dan hati. Ekskresi Timbal $(\mathrm{Pb})$ terbatas, maka sedikit saja peningkatan asupan setiap sehari dapat menimbulkan akumulasi timbal.

Keracunan Timbal $(\mathrm{Pb})$ akut dapat ditandai dengan kadar lebih dari 0,72 ppm dalam darah. Penyerapan timbal $(\mathrm{Pb})$ dengan cepat menyebabkan syndrome syok yang juga disebabkan oleh kehilangan cairan lewat saluran cerna. Sedangkan untuk susunan syaraf, timbal $(\mathrm{Pb})$ dapat menyebabkan parestesia, nyeri, dan kelemahan otot. Timbal $(\mathrm{Pb})$ dapat juga menyebabkan gangguan fungsi reproduksi yang mengakibatkan kemandulan, aborsi, dan kematian janin. Untuk keracunan timbal $(\mathrm{Pb})$ kronis, dapat ditandai dengan adanya kerusakan ginjal dan bahkan kematian yang terjadi dalam $1-2$ hari.

Novebry et al, 2015, telah melakukan penelitian pada sediaan Eyeliner pencil dan menemukan adanya timbal pada Eye-liner pencil yang beredar di Kota Pontianak dengan merek yang berbeda. Hasil penelitian tersebut diperoleh kadar timbal dari lima sampel yang positif dengan kadar 4,0157, $1,5480, \quad 0,9136, \quad 1,0739, \quad 0,9961 \mu \mathrm{g} / \mathrm{g}$ (ppm).

Dari hasil penelitian itu disimpulkan bahwa kadar timbal yang terkandung dalam sampel masih jauh di bawah batas maksimum yang ditentukan BPOM Nomor 17 Tahun 2014 Tentang Perubahan Atas Peraturan Kepala Badan Pengawas Obat dan Makanan Nomor HK.03.1.23.07.11.6662 Tahun 2011 Tentang Persyaratan Cemaran Mikroba dan Logam Berat Dalam Kosmetika untuk Timbal/Timah Hitam $(\mathrm{Pb})$, tidak boleh lebih dari $20 \mathrm{mg} / \mathrm{kg}$ atau $20 \mathrm{mg} / \mathrm{L} \mathrm{(20}$ bpj).

Oleh karena itu peneliti tertarik mengembangkan penelitian sebelumnya dengan mengunakan jenis Eye-liner liquid karena memiliki warna yang lebih pekat, tahan lama atau tahan air (Waterproof) daripada Eye-liner Pencil.

Berdasarkan uraian di atas, maka dilakukan penelitian tentang penetapan kadar logam berat Timbal $(\mathrm{Pb})$ pada EyeLiner yang beredar di Kota Makassar dengan menggunakan metode Spektrofotometri Serapan Atom (SSA).

\section{METODE PENELITIAN}

Lokasi pengambilan sampel

Sampel berupa Eye-Liner Liquid yang beredar di Kota Makassar, Sulawesi Selatan. Pengambilan sampel dilakukan secara langsung di Pasar Tradisional Kota Makassar dan dikumpulkan dengan cara Purpossive Sampling yang akan dianalisis di Balai Besar Laboratorium Kesehatan (BBLK) Makassar, Sulawesi Selatan.

\section{Alat dan bahan}

Alat yang digunakan yaitu Spektrofotometer Serapan Atom (SSA), lemari asam, gelas kimia, pipet ukur, ball filler, cawan porselin, labu ukur, corong gelas, hot plate, neraca analitik, kertas saring whatman No. 40, pipet tetes, batang pengaduk, sendok tanduk, tissue, corong, dan lap. 
Bahan yang digunakan yaitu Eyeliner liquid, akuades, asam nitrat $\left(\mathrm{HNO}_{3}\right)$ $2 \%$, dan $\mathrm{HNO}_{3}(\mathrm{P})$.

\section{Persiapan Sampel Eye-Liner}

Sampel Eye-liner Liquid ditimbang sebanyak $\pm 0,5 \mathrm{~g}$ ke dalam cawan porselin kemudian di lakukan dekstruksi kering sebanyak 2 kali pada suhu $600^{\circ} \mathrm{C}$ yang bertujuan untuk mengabukan sampel, kemudian ditambahkan $\mathrm{HNO}_{3}(\mathrm{P}) 1 \mathrm{~mL}$ lalu dipanaskan pada hot plate hingga uap berwarna putih, kemudian didinginkan dan ditambahkan dengan akuadest $15 \mathrm{~mL}$ lalu diaduk kemudian disaring, filtratnya ditampung dalam labu ukur $25 \mathrm{~mL}$, ditepatkan volumenya dengan akuades, dihomogenkan kemudian ditampung dalam botol sampel.

Penetapan Kadar Logam Timbal (Pb) dari Sampel Eye-Liner dengan Metode Spektrofotometri Serapan Atom (SSA)

Dipipet larutan baku timbal (Pb) 1000 $\mathrm{mg} / \mathrm{L}$ sebanyak $0 \mu \mathrm{L} ; 10 \mu \mathrm{L} ; 20 \mu \mathrm{L} ; 30$ $\mu \mathrm{L} ; 40 \mu \mathrm{L} ; 50 \mu \mathrm{L}$ diencerkan dengan $\mathrm{HNO}_{3} 2 \%$ dalam labu ukur $50 \mathrm{~mL}$ sampai tanda batas secara otomatis oleh alat hingga volume $1000 \mu \mathrm{L}(1 \mathrm{~mL})$, sehingga diperoleh konsentrasi logam timbal $0,0 \mu \mathrm{g} / \mathrm{L} ; 10 \mu \mathrm{g} / \mathrm{L} ; 20 \mu \mathrm{g} / \mathrm{L} ; 30$ $\mu \mathrm{g} / \mathrm{L} ; 40 \mu \mathrm{g} / \mathrm{L} ; 50 \mu \mathrm{g} / \mathrm{L}$. Setelah itu, larutan kerja yang dibuat akan diukur pada panjang gelombang 283,3 $\mathrm{nm}$. Kenudian dibuat kurva kalibrasi untuk mendapatkan persamaan garis regresi dan dilanjutkan dengan pengukuran sampel yang sudah dipersiapkan dengan prosedur kerja sama dengan larutan kerja logam timbal $(\mathrm{Pb})$.

\section{HASIL PENELITIAN}

Berdasarkan hasil penelitian penetapan kadar timbal $(\mathrm{Pb})$ pada Eyeliner Liquid yang beredar di Kota Makassar yang dilakukan di Balai Besar Laboratorium Kesehatan Makassar, sebanyak 5 sampel yang telah diambil secara purposive sampling yang diperoleh dari beberapa penjual yang beredar di Kota Makassar. Penetapan kadar logam berat timbal $(\mathrm{Pb})$ dari sampel Eye-liner Liquid dilakukan dengan metode
Spektrofotometri Serapan Atom (SSA) dengan panjang gelombang 283, $3 \mathrm{~nm}$. Hasil penelitian dapat di lihat pada tabel 1.

Tabel 1. Hasil Penetapan Kadar Logam Berat Timbal (Pb) dari Sampel Eye-Liner Liquid

\begin{tabular}{ccc}
\hline $\begin{array}{c}\text { Kode } \\
\text { Sampel }\end{array}$ & Satuan & $\begin{array}{c}\text { Kadar Logam } \\
\text { Timbal }(\mathbf{P b})\end{array}$ \\
\hline Sampel A & $\mathrm{mg} / \mathrm{kg}$ & 2,2215 \\
Sampel B & $\mathrm{mg} / \mathrm{kg}$ & 0,9226 \\
Sampel C & $\mathrm{mg} / \mathrm{kg}$ & 18,7713 \\
Sampel D & $\mathrm{mg} / \mathrm{kg}$ & 1,2215 \\
Sampel E & $\mathrm{mg} / \mathrm{kg}$ & 5,7021 \\
\hline
\end{tabular}

Sumber: Balai Besar Laboratorium Kesehatan (BBLK)

Pada penelitian ini prosedur kerja yang dilakukan pertama yaitu menimbang sampel Eye-liner sebanyak $\pm 0,5 \mathrm{~g}$ kemudian sampel didekstruksi kering pada suhu $600^{\circ} \mathrm{C}$ sebanyak 2 kali yang bertujuan untuk mengabukan sampel, kemudian ditambahkan larutan $\mathrm{HNO}_{3}(\mathrm{P})$ sebanyak $1 \mathrm{ml}$ yang berfungsi untuk mendestruksi sampel yang dimana senyawa lain yang bukan logam menghilang. Kemudian dipanaskan pada hot plate hingga uap berwarna putih, kemudian didinginkan lalu disaring menggunakan kertas saring setelah itu dibaca menggunakan alat SSA.

Penelitian logam berat timbal $(\mathrm{Pb})$ pada Eye-liner dengan menggunakan Spektrofotometer Serapan Atom (SSA) yang mempunyai prinsip kerja adalah bila cahaya (monokromatik maupun campuran) jatuh pada suatu medium homogen, sebagian dari sinar masuk akan dipantulkan, sebagian diserap dalam medium itu dan sisanya diteruskan.

Nilai yang keluar dari cahaya yang diteruskan dinyatakan dalam nilai absorbansi karena memiliki hubungan dengan konsentrasi sampel. Kemudian diperoleh absorbansi sampel dengan panjang gelombang maksimum $283,3 \mathrm{~nm}$, setalah itu dibuat grafik linear antara konsentrasi (x) dengan absorbansi (y) dari larutan standar sehingga diperoleh 
persamaan regresi dari $y=b . x-a$. berdasarkan persamaan regresi larutan standar dihitung konsentrasi untuk larutan sampel sehingga diperoleh kadar logam timbal $(\mathrm{Pb})$ dari sampel Eye-liner Liquid.

Berdasarkan penelitian yang telah dilakukan diperoleh hasil kadar logam berat timbal $(\mathrm{Pb})$ dari sampel Eye-liner pada masing-masing sampel dengan jumlah sampel yang ditimbang $\pm 0,5 \mathrm{~g}$ adalah sampel A sebesar 2,2215 $\mu \mathrm{g} / \mathrm{g}$, sampel B sebesar $0,9226 \mu \mathrm{g} / \mathrm{g}$, sampel C sebesar 18,7713 $\mu \mathrm{g} / \mathrm{g}$, sampel D sebesar $1,2215 \mu \mathrm{g} / \mathrm{g}$, sampel E sebesar 5,7021 $\mu \mathrm{g} / \mathrm{g}$ atau $\mathrm{mg} / \mathrm{kg}$.

Berdasarkan hasil penelitian diatas menunjukkan bahwa dari 5 sampel yang diteliti semuanya positif mengandung logam berat timbal $(\mathrm{Pb})$. Sampel dengan nilai tertinggi yaitu sampel $\mathrm{C}$ dan $\mathrm{E}$ kadar yang tinggi ini dimungkinkan adanya penambahan timbal $(\mathrm{Pb})$ sebagai bahan dasar atau pengotor ( Fernier, 2001), sedangkan sampel yang terendah yaitu sampel B yang dimungkinkan karena adanya cemaran yang berasal dari proses pengolahan, penyimpanan, dan atau terbawa dari bahan baku ( Novebry et al, 2015). Tetapi sampel tersebut tidak melebihi batas maksimum yang ditetapkan oleh BPOM RI Nomor HK.03.1.23.07.11.6662 yaitu sebesar 20 $\mathrm{mg} / \mathrm{kg}$.

Dampak logam timbal $(\mathrm{Pb})$ pada kesehatan bersifat kronis dan akut. Keracunan akut ditandai dengan gangguan kesehatan berupa mual, muntah, dengan muntahan menyerupai susu karena $\mathrm{Pb}$ klorida, dan sakit perut hebat, tinja berwarna hitam karena $\mathrm{Pb}$ sulfide, dapat disertai diare atau konstipasi, sedangkan gangguan kronis berupa sindrom yaitu sindrom abdominal, neorumuskular, SSP, hematologi, renal, dan sindrom lain (muka warna kelabu dan bibir pucat, bercak retina, tanda ketuaan dini, dll). Gejala ini sebagian atau semua sekaligus. Sindrom neuromuscular dan sindrom SSP terjadi pada pemejanan hebat, sementara sindrom abdominal merupakan manifestasi yang timbul perlahan-lahan.

\section{KESIMPULAN DAN SARAN}

Berdasarkan penelitian yang telah dilakukan untuk mengetahui Kadar Logam Berat Timbal $(\mathrm{Pb})$ Pada Eye-liner Liquid dengan mengunakan metode Spektrofotometri Serapan Atom (SSA) diperoleh hasil yaitu: sampel A sebanyak $2,2215 \mathrm{mg} / \mathrm{kg}$, sampel B sebanyak 0,9226 $\mathrm{mg} / \mathrm{kg}$, sampel C sebanyak 18,7713 $\mathrm{mg} / \mathrm{kg}$, sampel D sebanyak 1,2215 mg/kg, dan sampel E sebanyak $5,7021 \mathrm{mg} / \mathrm{kg}$.

Sampel Eye-liner Liquid yang beredar di Kota Makassar tersebut masih aman untuk digunakan karena masih berada dibawah kadar maksimal yang ditentukan BPOM yakni sebesar 20 $\mathrm{mg} / \mathrm{kg}$.

\section{DAFTAR PUSTAKA}

Agustina, L. K., 2017. Deteksi Kandungan Timbal Pada Lipstick Yang Dijual Di Pasar Legi Jombang Dengan Metode Spektrofotometer Serapan Atom. Karya Tulis Ilmiah (KTI). Jombang. Program Diploma III Analis Kesehatan Sekolah Tinggi Ilmu Kesehatan Insan Cendekia Medika.

Badan Pengawas Obat dan Makanan Republik Indonesia. 2014.

Peraturan Kepala Badan

Pengawas Obat dan Makanan Republik Indonesia Nomor HK.03.1.23.07.11.6662 Tahun 2011 Tentang Persyaratan Cemaran Mikroba dan Logam Berat (Merkuri, Timbal, Arsen, Kadmium) dalam Kosmetika. Jakarta. BPOMAdiwisastra, A. 1987. Keracunan. Penerbit Angkasa, Bandung.

Boybull dan Iis, Haryati. 2009. Analisis Unsur Pengotor $\mathrm{Fe}, \mathrm{Cr}$, Dan $\mathrm{Ni}$ Dalam Larutan Uranil Nitrat Menggunakan Spektrofotometer Serapan Atom. Sdm Teknologi Nuklir. ISSN 1978-0176. 
BPOM. 2011. Peraturan Kepala Badan Pengawas Obat dan Makanan Republik Indonesia. Tentang Metode Analisis Kosmetika. Jakarta : Sekretariat Negara.

Darmono, 2009. Farmasi Forensik dan Toksikologi. Universitas Indonesia. Indonesia. Jakarta.

Endrinadi, 2009. Logam-Logam Berat Pencemar Lingkungan dan Efek Terhadap Manusia. (Online), www.google.co.id. Di unduh 05 maret 2019.

Gandjar dan Rohman, 2007. Kimia Farmasi Analisis. Pustaka Pelajar.Jakarta.

Kusantati, H., et al. 2008. Tata Kecantikan Kulit Untuk Sekolah Menengah Kejuruan. Jilid 3. Direktorat Pembinaan Sekolah Menengah Kejuruan, Direktorat Jendral Manajemen Pendidikan Dasar dan Menengah, Depertemen Pendidikan Nasional. Jakarta.

Khopkar, S. M. 2010. Konsep Dasar Kimia Analitik. Jakarta : UI-Press. Mitsui, T. 1997. New Cosmetic Science. Edisi Kesatu. Amsterdam: Elsevier Science B.V. Hal.13,19-2.

Mutmainnah, 2015. Identifikasi Plumbum (Pb) Pada Beberapa Shampo Yang Diperdagangkan Di Kota Makassar. Akademi Analis
Kesehatan Muhammadiyah Makassar.

Novebry et al., 2015. Analis is Logam Timbal dalam Eye-liner Pencil Yang Beredar di Kota Pontianak. Jurnal FK Untan. Vol.1 No. 1. Hal 47-52.

Priyanto, 2010. Toksikologi, Mekanisme, Terapi Antidotum, dan Penelitian Risiko. Leskonfi ( Lembaga Studi Dan Konsultasi Farmkologi ). Depok

Palar. H 2012. Pencemaran dan Toksikologi Logam Berat. Rineka Cipta. Jakarta.

Tangahu, Bieby V. et al. 2011. A Review on Heavy Metals (As, $\mathrm{Pb}$, an $\mathrm{Hg}$ ) Uptake by Plants Through Phytoremediation. International Journal of Chemical Engineering : $1-32$.

Winanti, Tri. 2011. Kosmetik Dekoratif. (Online),

http://www.scribd.com/doc/542471 08/ Kosmetik-Dekoratif, Diakses 25 Februari 2019.

Widowati, W., Sastiono, A., dan Jusuf, R. 2008. Efek Toksik Logam Pencegahan Dan Penanggulangan Pencemaran. Andi Yogyakarta. Yogyakarta 